\title{
Fatigue life extension of epoxy materials using ultrafast epoxy-SbF 5 healing system introduced by manual infiltration
}

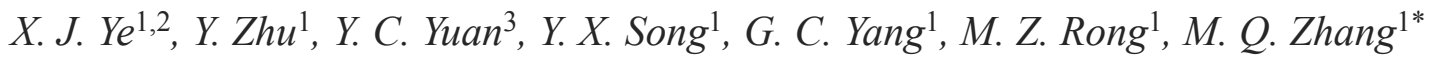 \\ ${ }^{1}$ Key Laboratory for Polymeric Composite and Functional Materials of Ministry of Education, GD HPPC Lab, School of \\ Chemistry and Chemical Engineering, Sun Yat-Sen University, 510275 Guangzhou, P. R. China \\ ${ }^{2}$ Guangdong Provincial Public Laboratory of Analysis and Testing Technology, China National Analytical Center, 510070 \\ Guangzhou, P. R. China \\ ${ }^{3}$ College of Materials Science and Engineering, South China University of Technology, 510640 Guangzhou, P. R. China
}

Received 7 September 2014; accepted in revised form 7 November 2014

\begin{abstract}
The present paper is devoted to the verification of the capability of epoxy-SbF 5 system as a healing chemistry for rapidly retarding and/or arresting fatigue cracks in epoxy materials at room temperature. Owing to the very fast curing

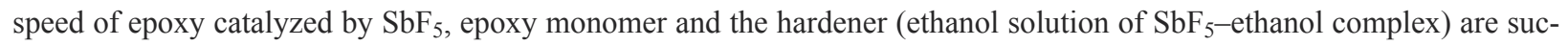
cessively infiltrated into the fracture plane under cyclic loading during the tension-tension fatigue test. As a result, the mechanisms including hydrodynamic pressure crack tip shielding, polymeric wedge and adhesive bonding of the healing agent are revealed. It is found that the healing agent forms solidified wedge at the crack tip within $20 \mathrm{~s}$ after start of polymerization of the epoxy monomer, so that the highest healing effect is offered at the moment. The epoxy-SbF 5 system proves to be effective in rapidly obstructing fatigue crack propagation (despite that its cured version has lower fracture toughness than the matrix), and satisfies the requirement of constructing fast self-healing polymeric materials.
\end{abstract}

Keywords: smart polymers, fracture and fatigue, self-healing, epoxy

\section{Introduction}

Polymers and polymer composites used for structural application are often subjected to cyclic loading. As a result, fatigue cracks might start to grow at a stress intensity that is significantly lower than the critical stress intensity $[1,2]$. To prevent the catastrophic failure of these materials under the circumstances, integration of self-healing capability within the system has been explored [3, 4].

Brown et al. [5] examined the effect of fluidic dicyclopentadiene (DCPD) on fatigue life extension of cured epoxy. The chemical was manually infiltrated into the crack tip of tapered double cantilever beam (TDCB) specimen. Viscous flow of DCPD in the crack plane retarded crack growth, and its polymerized version further acted as a wedge at the crack tip for artificial crack closure. In a latter report of the same group of authors [6], DCPD-loaded microcapsules and particulate Grubbs' catalyst were embedded in epoxy to fabricate self-healing epoxy. It allowed for responding to propagating fatigue cracks by autonomic processes that led to higher endurance limit and life extension, or even complete arrest of crack.

Subsequently, epoxy filled with the dual-microcapsules consisting of epoxy-capsules and mercaptan/tertiary amine-capsules also exhibited in-situ fatigue crack retardancy at room temperature [7]. The mech-

\footnotetext{
*Corresponding author, e-mail: ceszmq@mail.sysu.edu.cn

(c) BME-PT
} 
anisms of hydrodynamic pressure crack tip shielding, polymeric wedge and adhesive bonding of the healing agent were revealed $[7,8]$. Very recently, Neuser and Michaud [9] showed the fatigue response of the epoxy resin containing ethyl phenylacetate (EPA)-capsules. Diffusion of EPA solvent into the crack tip induced local plasticization of the epoxy and hence stopped cracking.

In addition to the strategy based on microencapsulated healing agent, thermoplastic poly(ethylene-comethacrylic acid) (EMAA) particles and fibers were respectively added into carbon fiber/epoxy laminates [10]. The thermally activated healing at $150^{\circ} \mathrm{C}$ of double cantilever beam (DCB) after fatigue test fully restored the fatigue resistance of delamination cracks. Infusion of EMAA along the crack plane under the high pressure delivery mechanism and strong EMAA/epoxy bonding were believed to account for the rehabilitation. James et al. [11] dispersed zirconium titanate powder in $\mathrm{Zn}$ ionomer to form a piezoelectric composite. The degraded piezoelectric property after high strain tensile cyclic loading was found to be recovered to a significant degree upon annealing at $70^{\circ} \mathrm{C}$ due to the thermal healing capability of $\mathrm{Zn}$-containing ionomer matrix. In fact, the approach no longer belongs to the extrinsic selfhealing as most works discussed above, but intrinsic self-healing [12].

Considering the fact that the extent and speed of mechanical properties restoration are equally important, but the latter factor has not yet aroused intense interest [13-16], the authors applied epoxy-SbF 5 cure as the healing chemistry for cured epoxy [17]. The epoxy composite with embedded epoxy-capsules [18] and $\mathrm{SbF}_{5} \cdot \mathrm{HOC}_{2} \mathrm{H}_{5} / \mathrm{HOC}_{2} \mathrm{H}_{5}$ (ethanol solution of $\mathrm{SbF}_{5}$-ethanol complex)-capsules [19] proved to be able to re-bonding cracked epoxy within seconds. To have better understanding of the role of the epoxy-SbF 5 system under cyclic loading, manual infiltration of the healing agent at crack tip of cured epoxy is investigated in this work. The knowledge might benefit further development of ultrafast selfhealing polymeric materials for practical usage.

\section{Experimental}

\subsection{Materials}

Epoxy, diglycidyl ether of bisphenol A (trade name: EPON 828; epoxy equivalent mass: $188 \mathrm{~g} / \mathrm{mol}$ ), was purchased from Shell Co., acting as both the composite's matrix and the polymerizable component of healing agent. $\mathrm{SbF}_{5}$ was supplied by Tianjin Institute of Physical and Chemical Engineering of Nuclear Industry, China. Methyl hexahydrophthalic anhydride (MHHPA, anhydride equivalent mass: $168 \mathrm{~g} / \mathrm{mol}$ ) and borontrifluoride-2,4-dimethylaniline-complex $\left(\mathrm{BF}_{3} \cdot \mathrm{DMA}\right)$ were supplied by Energy Chemical, Shanghai, China.

\subsection{Specimen preparation}

TDCB specimens with groove length of $55 \mathrm{~mm}$ [20, 21] were cast from the stoichiometric mixture of 100 parts EPON 828, 80 parts curing agent MHHPA and 5 parts accelerant $\mathrm{BF}_{3} \cdot \mathrm{DMA}$. The compound was firstly degassed, and then poured into a preheated closed silicone rubber mold and cured at $50^{\circ} \mathrm{C}$ for $60 \mathrm{~h}$ and $70^{\circ} \mathrm{C}$ for $12 \mathrm{~h}$.

$\mathrm{SbF}_{5} \cdot \mathrm{HOC}_{2} \mathrm{H}_{5} / \mathrm{HOC}_{2} \mathrm{H}_{5}$ (concentration of $\mathrm{SbF}_{5}=$ $5 \mathrm{wt} \%$ ), the hardener component of the healing agent, was prepared by the method mentioned in ref. [17].

\subsection{Characterization}

Healing of the materials under cyclic stress was studied during fatigue test on the TDCB specimens with a Shimadzu air servo fatigue and endurance testing system ADT-AV02K1S5 at room temperature $\left(25^{\circ} \mathrm{C}\right)$. The specimens were pre-cracked $(\sim 2.5 \mathrm{~mm}$ long$)$ by a razor blade while ensuring the pre-crack tip was centered in the groove. A triangular waveform of $5 \mathrm{~Hz}$ was applied with a stress ratio, $R$, of $0.1(R=$ $K_{\min } / K_{\max }$, where $K_{\min }$ and $K_{\max }$ denote the minimum and maximum values of the cyclic stress intensity, respectively). Fatigue cracks were grown within constant mode-I stress intensity factor range, $\Delta K_{\mathrm{I}}\left(\Delta K_{\mathrm{I}}=\right.$ $\left.K_{\max }-K_{\min }\right)$. The optically measured crack tip position and specimen compliance were plotted against number of cycles. The linear relationship between optically measured crack length and specimen compliance was used to calculate the crack tip position of the specimens at all times during the experiment [6]. Healing efficiency, $\lambda$, was defined by fatigue life extension [5]: $\lambda=\left(N_{\text {healed }}-N_{\text {control }}\right) / N_{\text {control }}$, where $N_{\text {healed }}$ and $N_{\text {control }}$ denote the total number of cycles to failure of the healed specimen and that of a similar control specimen without healing, respectively. The manual infiltration of the healing agent was conducted as follows. About $0.5 \mu \mathrm{L}$ EPON 828 was injected into the crack plane by using a microsyringe after a crack growth increment of about $8 \mathrm{~mm}$. In this case, both the growth rate and crack closure response settled down to steady state values. The 
injection was completed within $5 \mathrm{~s}$. With the repeated opening and closing of the fracture plane, the infiltrated epoxy flowed backward and forward and instantaneously evenly penetrated into the crack. Thereby the effect of hydrodynamic pressure crack tip shielding could be observed. Furthermore, the effects of polymeric wedge and adhesive bonding of the healing agent were studied by injecting $0.5 \mu \mathrm{L}$ $\mathrm{SbF}_{5} \cdot \mathrm{HOC}_{2} \mathrm{H}_{5} / \mathrm{HOC}_{2} \mathrm{H}_{5}$ into the crack plane about $60 \mathrm{~s}$ after the injection of EPON 828. For each test, the result was an average of five specimens. Temperature variation at the crack tip was monitored by an infrared camera ImageIR ${ }^{\circledR} 8300$ (InfraTec GmbH, Germany). Morphologies of the fracture surfaces were observed by a Hitachi Model S-4800 field emission scanning electron microscope (SEM).

\section{Results and discussion}

\subsection{Effect of hydrodynamic pressure crack-tip shielding}

In our previous work on the epoxy composite filled with epoxy monomer loaded microcapsules and $\mathrm{SbF}_{5} \cdot \mathrm{HOC}_{2} \mathrm{H}_{5} / \mathrm{HOC}_{2} \mathrm{H}_{5}$ loaded microcapsules [17], the healing agent was found to be liberated upon fracture of the specimen, spreading over the fractured surface and rejoining the broken specimen at room temperature. Due to the very fast curing characteristic of the healing system, however, the effect of hydrodynamic pressure crack-tip shielding cannot be clearly identified. For this purpose, uncured epoxy component of the healing agent alone was firstly injected into the crack plane without the interference of any hardener.

It has been known that the forces required to drive viscous liquid into the crack during loading and to draw the fluid out of the crack during unloading would provide effective crack-tip shielding [22, 23]. This hydrodynamic pressure effect decreases the effective mode-I stress intensity factor range, $\Delta K_{\text {eff, }}$ and hence slows down the expansion of the fatigue crack and increases the fatigue life of materials. The dependences of fatigue crack length on loading cycle in Figure 1 illustrate the influence of the epoxy monomer on the fracture plane. Upon the injection of the fluidic epoxy monomer, the rate of crack growth remarkably declines as compared with that of the control specimen. As a result, the infiltrated specimen fails after $3.6 \cdot 10^{5}$ cycles instead of $2.1 \cdot 10^{5}$ cycles, leading to a fatigue life extension of $73.5 \%$.

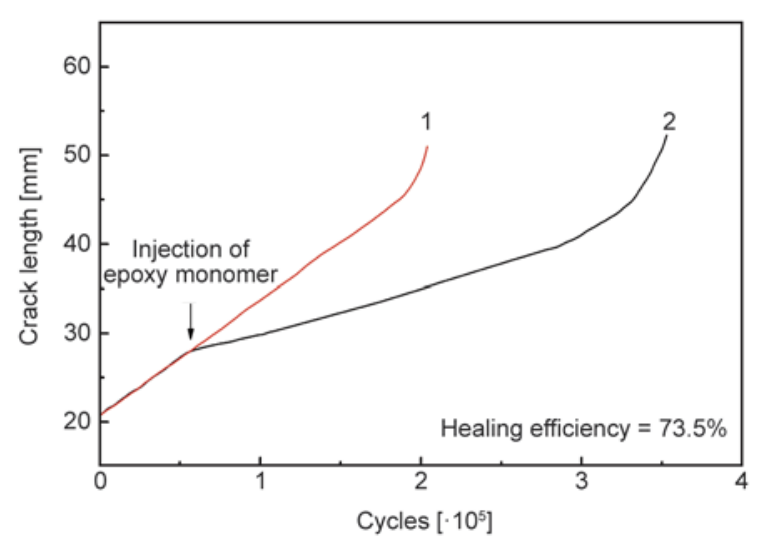

Figure 1. Crack length vs. fatigue cycles of (1) control specimen and (2) the specimen with manually injected epoxy monomer. Testing condition: $K_{\max }=$ $2.58 \cdot 10^{-1} \mathrm{MPa} \cdot \mathrm{m}^{1 / 2}\left(=0.56 K_{\mathrm{IC}}\right.$ of the matrix $)$, $K_{\min }=2.60 \cdot 10^{-2} \mathrm{MPa} \cdot \mathrm{m}^{1 / 2}$, $\Delta K_{\mathrm{I}}=2.32 \cdot 10^{-1} \mathrm{MPa} \cdot \mathrm{m}^{1 / 2}$.

It is worth noting that our early study of manual infiltration of the same epoxy monomer, EPON 828 , into cured epoxy under cyclic loading yielded a fatigue life extension of $246 \%$ [8]. The difference should result from the different ductility of the matrix epoxy. In the present work, fracture toughness, $K_{\text {IC }}$, of the epoxy cured by MHHPA and $\mathrm{BF}_{3} \cdot$ DMA is $4.59 \cdot 10^{-1} \mathrm{MPa} \cdot \mathrm{m}^{1 / 2}$, which is lower than the value of the former cured by diethylenetriamine (i.e. $5.87 \cdot 10^{-1} \mathrm{MPa} \cdot \mathrm{m}^{1 / 2}$ ). Although the $\Delta K \mathrm{I}$ applied for the fatigue test of the current material is reduced to $2.32 \cdot 10^{-1} \mathrm{MPa} \cdot \mathrm{m}^{1 / 2}$, lower than that applied for the former material (i.e. $4.54 \cdot 10^{-1} \mathrm{MPa} \cdot \mathrm{m}^{1 / 2}$ ), the measured fatigue life extension is still lower. Clearly, the hydrodynamic pressure crack-tip shielding mechanism is less effective in more brittle material, which is more sensitive to the fatigue loading.

The load-displacement curve shown in Figure 2 further shows the hydrodynamic pressure effect from another angle. Before injecting the epoxy monomer, the loading-unloading curves of the epoxy specimen recorded at each fatigue cycle overlap (refer to curves $a$ and $b$ in Figure 2). After injection of the epoxy monomer, the fatigue crack can neither be fully opened at the maximum load nor be fully closed at the minimum load. Consequently, hysteresis loops appear on the load-displacement relationship between the initial phase of crack opening and the end phase of crack closing (see curves c $\sim$ e in Figure 2). As the injected epoxy monomer has to inevitably adhere to the crack plane, the amount of the viscous fluid at the crack tip gradually decreases 

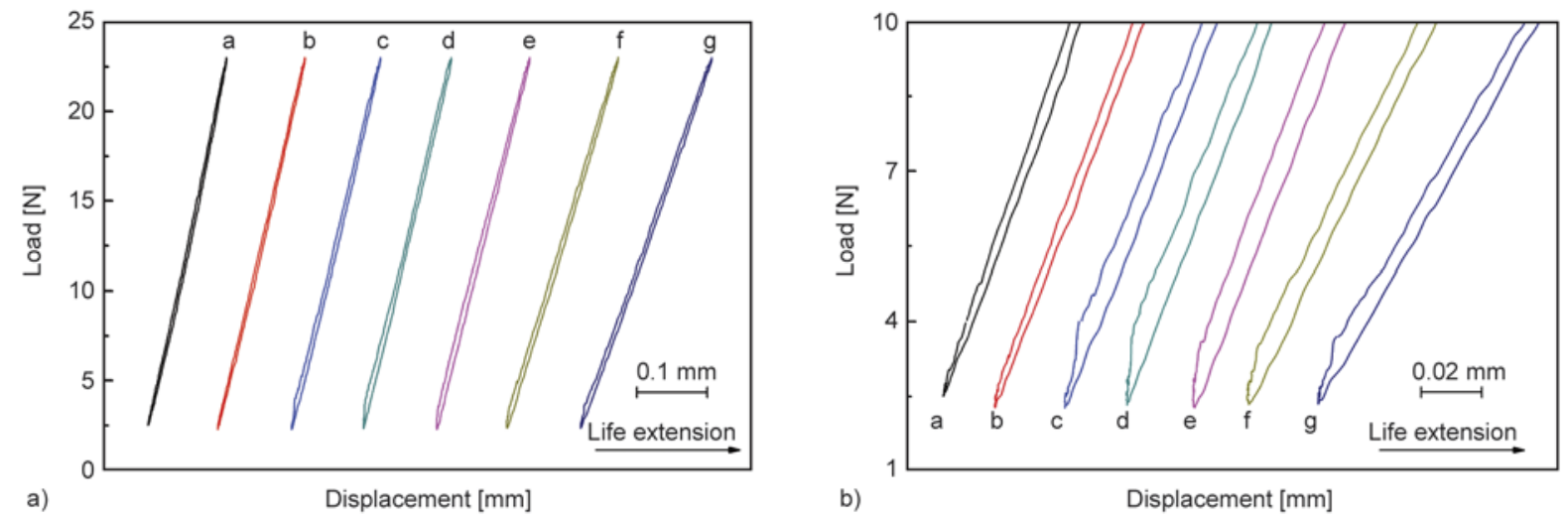

Figure 2. (a) Load-displacement curves measured during selected cycles of curve 2 in Figure 1. Number of the fatigue cycles and time after manual infiltration of the epoxy monomer: (a) 600; (b) 57 400; (c) $60000,0.5$ min; (d) 61 500, 5 min; (e) 101 400, 138.5 min; (f) 199 800, 466.5 min; (g) 299 400, 798.5 min. (b) Partially enlarged view of (a). Testing condition: $K_{\max }=2.58 \cdot 10^{-1} \mathrm{MPa} \cdot \mathrm{m}^{1 / 2}\left(=0.56 K_{\mathrm{IC}}\right.$ of the matrix), $K_{\min }=2.60 \cdot 10^{-2} \mathrm{MPa} \cdot \mathrm{m}^{1 / 2}$, $\Delta K_{\mathrm{I}}=2.32 \cdot 10^{-1} \mathrm{MPa} \cdot \mathrm{m}^{1 / 2}$.

with advance of crack. The hysteresis loops become thinner with time (refer to curves fand $g$ in Figure 2), representing weakening of the hydrodynamic pressure crack-tip shielding effect.

\subsection{Effects of polymeric wedge and adhesive bonding}

It has been known that the effective stress intensity factor range can be greatly reduced by a wedge with adhesiveness at the crack tip [24-26]. Here in this work, the wedge of crosslinked epoxy forms shortly after injection of $\mathrm{SbF}_{5} \cdot \mathrm{HOC}_{2} \mathrm{H}_{5} / \mathrm{HOC}_{2} \mathrm{H}_{5}$ into the fracture plane, because the epoxy monomer has been infiltrated in advance. Therefore, significant retardation of fatigue crack occurs (Figure 3a), leading to a fatigue life extension of $82.8 \%$, which is $\sim 9 \%$ higher than the value offered by merely injecting epoxy monomer (Figure 1). The marginal increase of the healing efficiency owing to the incorporation of

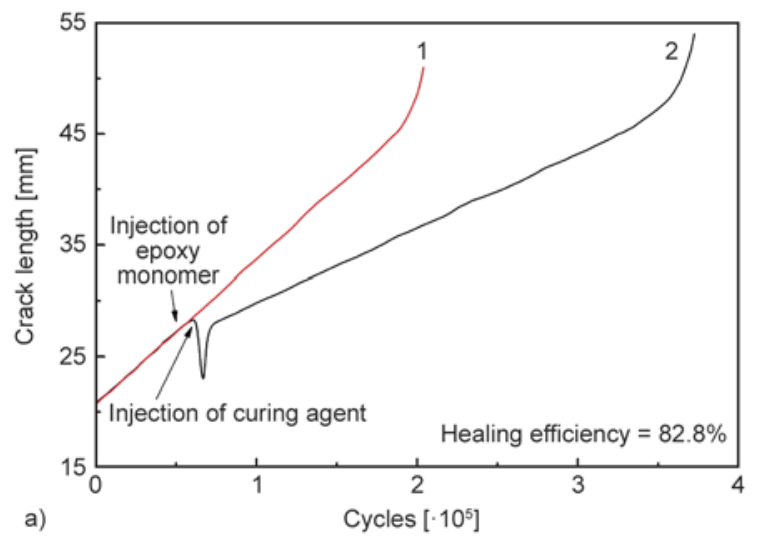

the hardener should be attributed to the incomplete polymerization of epoxy monomer in the case of the ultrafast curing speed. Fully developed network structure in conventional cured epoxy is absent in the present cured healing agent, so that the polymeric wedge and adhesive bonding effects become weaker in comparison with the case of slower curing speed [8]. It seems there is a dilemma that how the healing system can simultaneously provide high healing efficiency and high healing speed.

To have more detailed information of the crack growth behavior affected by the infiltrated healing agent, partially enlarged view of Figure $3 \mathrm{a}$ is plotted in Figure 3b. It is seen that after the injection of epoxy monomer but before the injection of the curing agent $\mathrm{SbF}_{5} \cdot \mathrm{HOC}_{2} \mathrm{H}_{5} / \mathrm{HOC}_{2} \mathrm{H}_{5}$, the aforesaid hydrodynamic pressure effect is present as characterized by the reduced slope of the dependences of fatigue crack length on loading cycle (refer to curve 2

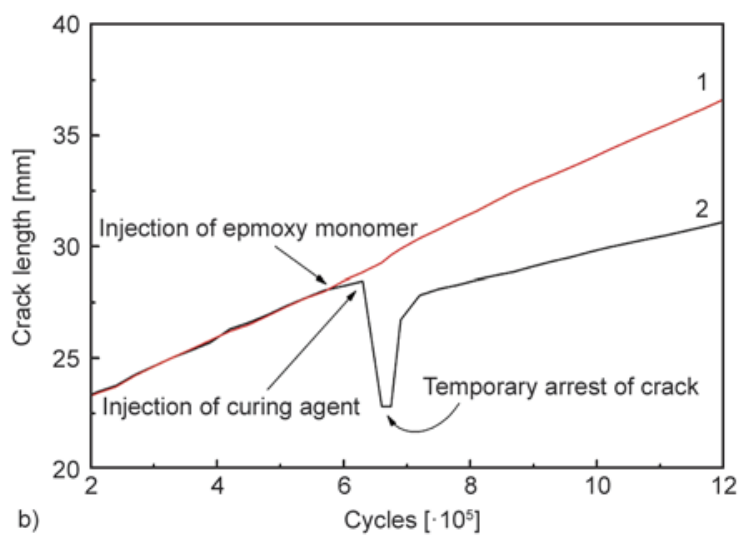

Figure 3. (a) Crack length vs. fatigue cycles of (1) control specimen and (2) the specimen with manually injected epoxy monomer and $\mathrm{SbF}_{5} \cdot \mathrm{HOC}_{2} \mathrm{H}_{5} / \mathrm{HOC}_{2} \mathrm{H}_{5}$. (b) Partially enlarged view of (a). Testing condition: $K_{\max }=$ $2.58 \cdot 10^{-1} \mathrm{MPa} \cdot \mathrm{m}^{1 / 2}\left(=0.56 K_{\mathrm{IC}}\right.$ of the matrix $), K_{\min }=2.60 \cdot 10^{-2} \mathrm{MPa} \cdot \mathrm{m}^{1 / 2}, \Delta K_{\mathrm{I}}=2.32 \cdot 10^{-1} \mathrm{MPa} \cdot \mathrm{m}^{1 / 2}$. 


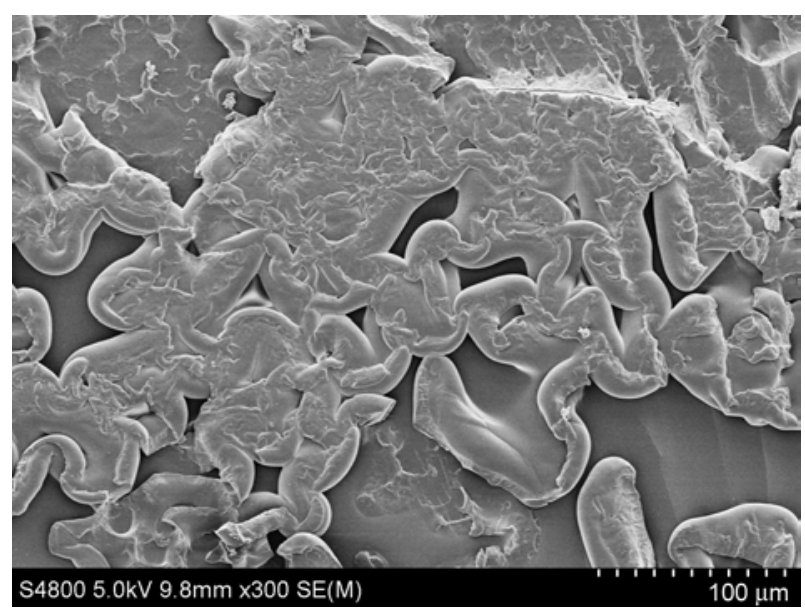

Figure 4. SEM micrograph of fatigue fracture surface of the specimen with successive manual injection of epoxy monomer and $\mathrm{SbF}_{5} \cdot \mathrm{HOC}_{2} \mathrm{H}_{5} / \mathrm{HOC}_{2} \mathrm{H}_{5}$

in Figure 3b). When the curing agent is injected, curing reaction of the epoxy monomer takes place rapidly. The infiltrated epoxy that flows backward in the course of crack closing is consolidated instantly, so that the measured crack length is shortened by about $6 \mathrm{~mm}$. Additionally, temporary arrest of fatigue crack also appear (refer to the terrace on curve 2 in Figure $3 b$ ).

With the proceeding of the fatigue test, the crack eventually travels through the polymeric wedge and leaves cohesively ruptured wedge behind (Figure 4). Due to the high affinity of the cured healing agent for the epoxy matrix, however, the remains of the ruptured wedge still stay on the cracked plane, and take effect to reduce the effective stress intensity factor range at the crack tip to a certain degree. It

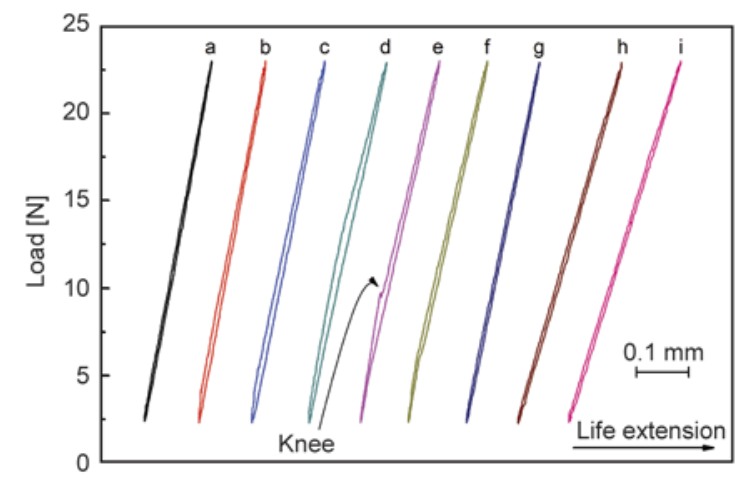

a)

Displacement [mm] explains the significantly lower crack growth rate of the majority of curve 2 in Figure 3 after injection of $\mathrm{SbF}_{5} \cdot \mathrm{HOC}_{2} \mathrm{H}_{5} / \mathrm{HOC}_{2} \mathrm{H}_{5}$, as compared with that of the control specimen (i.e. curve 1 in Figure 3).

To understand the time of the polymeric wedge formation, load-displacement relationships measured during selected cycles of curve 2 in Figure 3 are given in Figure 5. Prior to injection of the healing agent into the crack tip, nearly no hysteresis loop is detected (see curve a in Figure 5). Following the epoxy monomer injection, the fluid rapidly flows throughout the cracked plane and penetrates into the crack tip under cycling load. Accordingly, the hydrodynamic pressure effect comes into existence and hysteresis loop is evidently visible (curve b in Figure 5). When the curing agent $\mathrm{SbF}_{5} \cdot \mathrm{HOC}_{2} \mathrm{H}_{5} /$ $\mathrm{HOC}_{2} \mathrm{H}_{5}$ is injected into the crack plane, the preinjected epoxy monomer starts to be polymerized. As the fluidic healing agent becomes more and more viscous, the effect of hydrodynamic pressure crack tip shielding is enhanced and the areas of the hysteresis loops increase (curves $\mathrm{c}$ and $\mathrm{d}$ in Figure 5). Meanwhile, obvious tearing traces formed by the healing agent in the rubbery state are found on the fracture plane (Figure 4).

It is interesting to see that a knee point appears on the loading part of curve e in Figure 5, which results from the crack closure effect contributed by the polymeric wedge and adhesion at the crack tip [27]. In contrast, injection of epoxy monomer alone could not lead to the same effect (Figure 2), which evidences that the knee point is related to solidification

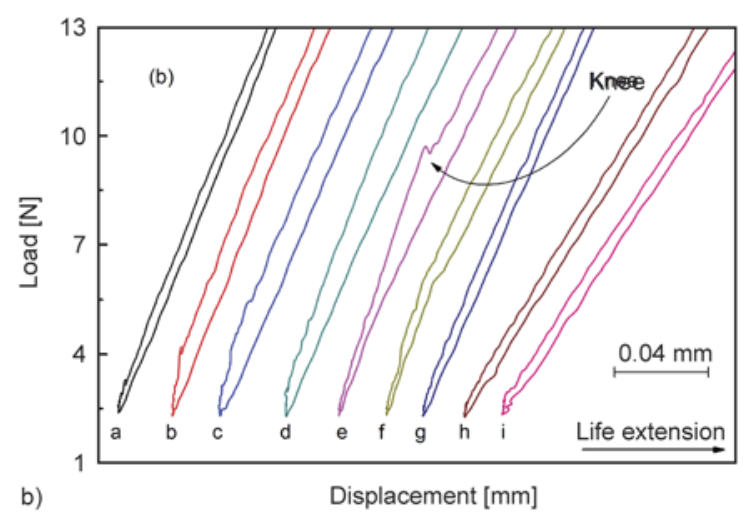

Figure 5. (a) Load-displacement curves measured during selected cycles of curve 2 in Figure 3. Number of the fatigue cycles and time after the manual infiltration of healing agent: (a) 54 000; (b) 60 000, 1 min after epoxy monomer injection; (c) 65 950, $10 \mathrm{~s}$ after injection of $\mathrm{SbF}_{5} \cdot \mathrm{HOC}_{2} \mathrm{H}_{5} / \mathrm{HOC}_{2} \mathrm{H}_{5}$; (d) 65 975, $15 \mathrm{~s}$; (e) 66 000, $20 \mathrm{~s}$; (f) 66025 , $25 \mathrm{~s}$; (g) 73 400, $25 \mathrm{~min}$; (h) 299 300, $998 \mathrm{~min}$; (i) 345 000, $1150 \mathrm{~min}$. The times indicated for curves (d) (i) represent those counting from the injection of the curing agent $\mathrm{SbF}_{5} \cdot \mathrm{HOC}_{2} \mathrm{H}_{5} / \mathrm{HOC}_{2} \mathrm{H}_{5}$. (b) Partially enlarged view of (a). Testing conditions: $K_{\max }=2.58 \cdot 10^{-1} \mathrm{MPa} \cdot \mathrm{m}^{1 / 2}\left(=0.56 K_{\mathrm{IC}}\right.$ of the matrix $), K_{\min }=2.60 \cdot 10^{-2} \mathrm{MPa} \cdot \mathrm{m}^{1 / 2}$, $\Delta K_{\mathrm{I}}=2.32 \cdot 10^{-1} \mathrm{MPa} \cdot \mathrm{m}^{1 / 2}$. 


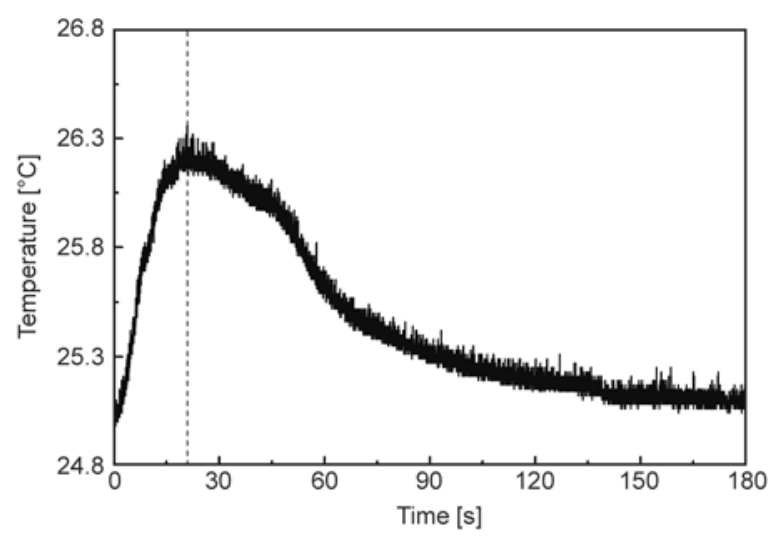

Figure 6. Time dependence of the temperature at fatigue crack tip of the specimen. The time is counted from injection of $\mathrm{SbF}_{5} \cdot \mathrm{HOC}_{2} \mathrm{H}_{5} / \mathrm{HOC}_{2} \mathrm{H}_{5}$. Epoxy monomer has been injected into the fracture plane prior to the injection of the curing agent.

of the injected healing agent. It can thus be concluded that the highest healing effect offered by the epoxy-SF 5 healing agent is achieved $20 \mathrm{~s}$ after their contact. With a further rise in time, the wedge is damaged and the effects of polymeric wedge and adhesive bonding have to be decreased. Not only the knee point disappears but also the areas of the hysteresis loops become smaller (refer to curves $\mathrm{f} \sim \mathrm{i}$ in Figure 5).

The rapid healing capability of the healing system revealed above is supported by the in-situ measurement of the temperature of the crack tip, which peaks at about $20 \mathrm{~s}$ (Figure 6). It means that the exothermic polymerization of the injected epoxy monomer happens as soon as it contacts $\mathrm{SbF}_{5} \cdot \mathrm{HOC}_{2} \mathrm{H}_{5} /$ $\mathrm{HOC}_{2} \mathrm{H}_{5}$ and the reaction degree reaches the maximum after $20 \mathrm{~s}$. As no additional reactants are supplemented, the heat given by the curing reaction gradually reduces with time.

\subsection{Effect of applied range of cyclic stress intensity}

In the course of fatigue test, healing chemical kinetics and crack growth rate are the major factors affecting the crack retardation performance of self-healing materials $[5,8]$. Considering that crack growth rate is closely related to stress intensity factor range, $\Delta K_{\mathrm{I}}$, crack growth behavior of the specimen was studied at additional two levels of applied range of stress intensity using manual infiltration of the healing agent (Figure 7), so as to have better understanding of the healing system. During the tests, the maximum cyclic stress intensity was changed, but the stress ratio, $R$, was kept at 0.1 .

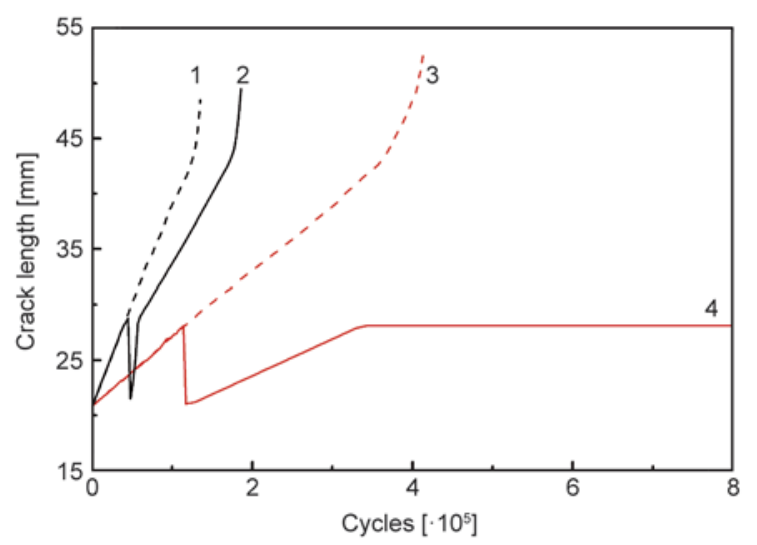

Figure 7. Crack length vs. fatigue cycles of control specimens (dashed lines) and the specimens with manually injected epoxy monomer and $\mathrm{SbF}_{5} \cdot \mathrm{HOC}_{2} \mathrm{H}_{5} /$ $\mathrm{HOC}_{2} \mathrm{H}_{5}$ (solid lines). Testing conditions: for curves 1 and $2, K_{\max }=2.80 \cdot 10^{-1} \mathrm{MPa} \cdot \mathrm{m}^{1 / 2}$ (=0.61 $K_{\mathrm{IC}}$ of the matrix), $K_{\min }=2.80 \cdot 10^{-2} \mathrm{MPa} \cdot \mathrm{m}^{1 / 2}$, $\Delta K_{\mathrm{I}}=2.52 \cdot 10^{-1} \mathrm{MPa} \cdot \mathrm{m}^{1 / 2}$; for curves 3 and 4 , $K_{\max }=2.24 \cdot 10^{-1} \mathrm{MPa} \cdot \mathrm{m}^{1 / 2}\left(=0.49 K_{\mathrm{IC}}\right.$ of the matrix), $K_{\min }=2.20 \cdot 10^{-2} \mathrm{MPa} \cdot \mathrm{m}^{1 / 2}$, $\Delta K_{\mathrm{I}}=2.02 \cdot 10^{-1} \mathrm{MPa} \cdot \mathrm{m}^{1 / 2}$.

For $K_{\max }=2.80 \cdot 10^{-1} \mathrm{MPa} \cdot \mathrm{m}^{1 / 2}\left(=0.61 K_{\mathrm{IC}}\right.$ of the matrix) that is higher than the value in Figure 3 (i.e. $\left.2.58 \cdot 10^{-1} \mathrm{MPa} \cdot \mathrm{m}^{1 / 2}\right)$, the repairing efficiency of the specimen is about $37.8 \%$ at room temperature relative to the control specimen. It is lower than $82.8 \%$ given in Figure 3 because (i) the mechanical kinetics of crack propagation is dominant in this case, and (ii) the polymeric wedge formed by the healing agent is easier to be destroyed by higher stress and the shielding effect of the crack tip has to be weakened accordingly.

When $K_{\max }$ is reduced to $2.24 \cdot 10^{-1} \mathrm{MPa} \cdot \mathrm{m}^{1 / 2}$ $\left(=0.49 K_{\mathrm{IC}}\right.$ of the matrix), the deformation rate and damaging of polymeric wedge are greatly slowed

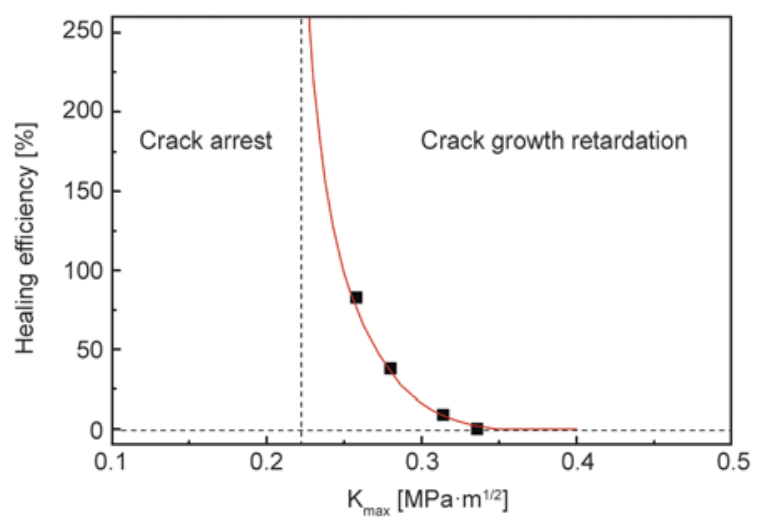

Figure 8. Healing efficiency of fatigue specimens vs. maximum cyclic stress intensity 
down, thus the healing kinetics predominates and the crack tip shielding effect is more apparent. The crack does not grow even when fatigue cycles are greater than $10^{7}$, meaning that it is arrested. The repair efficiency tends to be infinite. In contrast, the crack in the control specimen that cannot be healed develops at a constant speed. The maximum cyclic stress intensity of $\sim 2.24 \cdot 10^{-1} \mathrm{MPa} \cdot \mathrm{m}^{1 / 2}$ becomes the watershed between fatigue crack growth retardation and crack arrest (Figure 8).

\section{Conclusions}

By successive manual infiltration of epoxy monomer and $\mathrm{SbF}_{5} \cdot \mathrm{HOC}_{2} \mathrm{H}_{5} / \mathrm{HOC}_{2} \mathrm{H}_{5}$ into fracture plane of cured epoxy specimen subjected to cyclic loading, crack tip shielding effects resulting from hydrodynamic pressure, polymeric wedge and adhesive bonding are clearly identified. Under certain stress intensity factor range, the fatigue crack can even be fully arrested. More importantly, the healing agent proves to be converted into polymeric wedge within $20 \mathrm{~s}$ after the polymerization starts. This demonstrates the extremely fast operation feature of the healing system. The information helps to understand well the healing mechanisms of self-healing composites with dual microencapsulated healing agent under fatigue loading $[17,28]$, and to optimize the healant formulation accordingly. In authentic selfhealing composites, reaction of the healing agent released from ruptured microcapsules proceeds too fast to accurately analyze the healing mechanisms. Compared to the case with healing capsules [17], the fatigue life extension is less in the present work. This might be due the fact that the capsules rupture along the crack growth whereas the injection is done once. Accordingly, the fatigue crack retardation mechanisms (i.e. hydrodynamic pressure, polymeric wedge and adhesive bonding) appear repeatedly during the tests of the former material. In contrast, only the polymeric wedge still takes effect to a certain extent as crack passes the wedge in the pure epoxy specimen healed by manual infiltration. The difference highlights the role of individual factors in retarding fatigue crack propagation, and hence the usefulness of this work.

\section{Acknowledgements}

The authors thank the support of the Natural Science Foundation of China (Grants: 51273214 and 51333008), Doctoral Fund of Ministry of Education of China (Grant: 20090171110026), the Science and Technology Program of Guangdong Province (Grants: 2010B010800021, 2010A011300004, 2011A091102001, 2011A091102003 and S2013020013029), the Science and Technology Program of Guangzhou (Grant: 2014J4100121), and the Basic Scientific Research Foundation in Colleges and Universities of Ministry of Education of China (Grant: 12lgjc08).

\section{References}

[1] Karger-Kocsis J., Friedrich K.: Microstructure-related fracture toughness and fatigue crack growth behaviour in toughened, anhydride-cured epoxy resins. Composites Science and Technology, 48, 263-272 (1993).

DOI: 10.1016/0266-3538(93)90143-5

[2] Karger-Kocsis J., Friedrich K.: Fatigue crack propagation and related failure in modified, andhydride-cured epoxy resins. Colloid and Polymer Science, 270, 549562 (1992).

DOI: $10.1007 / \mathrm{BF} 00658286$

[3] Zhang M. Q., Rong M. Z.: Self-healing polymers and polymer composites. Wiley, Hoboken (2011).

[4] Yuan Y. C., Yin T., Rong M. Z., Zhang M. Q.: Self healing in polymers and polymer composites. Concepts, realization and outlook: A review. Express Polymer Letters, 2, 238-250 (2008).

DOI: $10.3144 /$ expresspolymlett.2008.29

[5] Brown E. N., White S. R., Sottos N. R.: Retardation and repair of fatigue cracks in a microcapsule toughened epoxy composite - Part I: Manual infiltration. Composites Science and Technology, 65, 2466-2473 (2005). DOI: 10.1016/j.compscitech.2005.04.020

[6] Brown E. N., White S. R., Sottos N. R.: Retardation and repair of fatigue cracks in a microcapsule toughened epoxy composite - Part II: In situ self-healing. Composites Science and Technology, 65, 2474-2480 (2005). DOI: $10.1016 /$ j.compscitech.2005.04.053

[7] Yuan Y. C., Rong M. Z., Zhang M. Q., Yang G. C., Zhao J. Q.: Self-healing of fatigue crack in epoxy materials with epoxy/mercaptan system. Express Polymer Letters, 5, 47-59 (2011).

DOI: 10.3144/expresspolymlett.2011.6

[8] Yuan Y. C., Rong M. Z., Zhang M. Q., Yang G. C., Zhao J. Q.: Healing of fatigue crack in epoxy materials with epoxy/mercaptan system via manual infiltration. Express Polymer Letters, 4, 644-658 (2010). DOI: 10.3144 /expresspolymlett.2010.79

[9] Neuser S., Michaud V.: Fatigue response of solventbased self-healing smart materials. Experimental Mechanics, 54, 293-304 (2014).

DOI: $10.1007 / \mathrm{s} 11340-013-9787-5$ 
[10] Pingkarawat K., Wang C. H., Varley R. J., Mouritz A. P.: Self-healing of delamination fatigue cracks in carbon fibre-epoxy laminate using mendable thermoplastic. Journal of Materials Science, 47, 4449-4456 (2012). DOI: $10.1007 / \mathrm{s} 10853-012-6303-8$

[11] James N. K., Lafont U., van der Zwaag S., Groen W. A.: Piezoelectric and mechanical properties of fatigue resistant, self-healing PZT-ionomer composites. Smart Materials and Structures, 23, 055001/1-055001/9 (2014). DOI: $10.1088 / 0964-1726 / 23 / 5 / 055001$

[12] Zhang M. Q., Rong M. Z.: Intrinsic self-healing of covalent polymers through bond reconnection towards strength restoration. Polymer Chemistry, 4, 4878-4884 (2013). DOI: $10.1039 / \mathrm{c} 3$ py00005b

[13] Xiao D. S., Yuan Y. C., Rong M. Z., Zhang M. Q.: Hollow polymeric microcapsules: Preparation, characterization and application in holding boron trifluoride diethyl etherate. Polymer, 50, 560-568 (2009).

DOI: 10.1016/j.polymer.2008.11.022

[14] Xiao D. S., Yuan Y. C., Rong M. Z., Zhang M. Q.: A facile strategy for preparing self-healing polymer composites by incorporation of cationic catalyst-loaded vegetable fibers. Advanced Functional Materials, 19, 2289-2296 (2009).

DOI: $10.1002 / \mathrm{adfm} .200801827$

[15] Xiao D. S., Yuan Y. C., Rong M. Z., Zhang M. Q.: Selfhealing epoxy based on cationic chain polymerization. Polymer, 50, 2967-2975 (2009).

DOI: $10.1016 /$ j.polymer.2009.04.029

[16] Xiao D. S., Rong M. Z., Zhang M. Q.: A novel method for preparing epoxy-containing microcapsules via UV irradiation-induced interfacial copolymerization in emulsions. Polymer, 48, 4765-4776 (2007). DOI: $10.1016 /$ j.polymer.2007.06.018

[17] Ye X. J., Zhang J-L., Zhu Y., Rong M. Z., Zhang M. Q., Song Y. X., Zhang H-X.: Ultrafast self-healing of polymer toward strength restoration. ACS Applied Materials and Interfaces, 6, 3661-3670 (2014). DOI: $10.1021 / \mathrm{am} 405989 \mathrm{~b}$

[18] Yuan Y. C., Rong M. Z., Zhang M. Q., Yang G. C.: Study of factors related to performance improvement of selfhealing epoxy based on dual encapsulated healant. Polymer, 50, 5771-5781 (2009). DOI: $10.1016 /$ j.polymer.2009.10.019
[19] Ye X-J., Ma Z-X., Song Y-X., Huang J-J., Rong M-Z., Zhang M-Q.: $\mathrm{SbF}_{5}$-loaded microcapsules for ultrafast self-healing of polymer. Chinese Chemical Letters, 25, 1565-1568 (2014). DOI: $10.1016 /$ j.cclet.2014.07.002

[20] Brown E. N., Sottos N. R., White S. R.: Fracture testing of a self-healing polymer composite. Experimental Mechanics, 42, 372-379 (2002).

DOI: $10.1177 / 001448502321548193$

[21] Brown E. N.: Use of the tapered double-cantilever beam geometry for fracture toughness measurements and its application to the quantification of self-healing. Journal of Strain Analysis for Engineering Design, 46, 167-186 (2011).

DOI: $10.1177 / 0309324710396018$

[22] Tzou J-L., Hsueh C. H., Evans A. G., Ritchie R. O.: Fatigue crack propagation in oil environments - II. A model for crack closure induced by viscous fluids. Acta Metallurgica, 33, 117-127 (1985).

DOI: 10.1016/0001-6160(85)90225-1

[23] Davis F. H., Ellison E. G.: Hydrodynamic pressure effects of viscous fluid flow in a fatigue crack. Fatigue and Fracture of Engineering Materials and Structures, 12, 527-542 (1989).

DOI: 10.1111/j.1460-2695.1989.tb00561.x

[24] Shin C. S., Cai C. Q.: A model for evaluating the effect of fatigue crack repair by the infiltration method. Fatigue and Fracture of Engineering Materials and Structures, 23, 835-845 (2000). DOI: $10.1046 / \mathrm{j} .1460-2695.2000 .00347 . \mathrm{x}$

[25] Sharp P. K., Clayton J. Q., Clark G.: Retardation and repair of fatigue cracks by adhesive infiltration. Fatigue and Fracture of Engineering Materials and Structures, 20, 605-614 (1997). DOI: $10.1111 / \mathrm{j} .1460-2695.1997 . t b 00292 . \mathrm{x}$

[26] Shin C. S., Hsu S. H.: Fatigue life extension by an artificially induced retardation mechanism. Engineering Fracture Mechanics, 43, 677-684 (1992). DOI: 10.1016/0013-7944(92)90210-6

[27] Wolf E.: Fatigue crack closure under cyclic tension. Engineering Fracture Mechanics, 2, 37-45 (1970). DOI: 10.1016/0013-7944(70)90028-7

[28] Ye X. J., Song Y. X., Zhu Y., Yang G. C., Rong M. Z., Zhang M. Q.: Self-healing epoxy with ultrafast and heat-resistant healing system processable at elevated temperature. Composites Science and Technology, 104, 40-46 (2014).

DOI: $10.1016 /$ j.compscitech.2014.08.028 